Eur. J. Clin. Chem. Clin. Biochem.

Vol. 30, 1992, pp. $775-778$

(C) 1992 Walter de Gruyter \& Co.

Berlin · New York

\title{
Concentrations in Serum of IgG, IgM and IgA and Their Age-Dependence in Beagle Dogs as Determined by a Newly Developed Enzyme-Linked-Immuno-Sorbent-Assay (ELISA)
}

\author{
By M. Schreiber, Dagmar Kantimm, Daniela Kirchhoff, G. Heimann and A. S. Bhargava
}

Research Laboratories, Schering AG, Experimental Toxicology, Berlin

(Received March 26/July 24, 1992)

\begin{abstract}
Summary: The concentrations of immunoglobulins IgG, IgM and IgA and their age dependence were determined in the serum of normal, untreated beagle dogs by a newly developed sandwich enzyme-linkedimmuno-sorbent-assay (ELISA). A clear age-dependent increase between $\approx 0.8$ and 1.6 years of age was observed for the immunoglobulin IgA, whereas IgG and IgM showed only a slight tendency to an agedependent increase. For immunotoxicological characterization of various compounds especially in long term studies, this IgA age-dependence has to be considered in the planning and interpretation of studies with beagle dogs.
\end{abstract}

\section{Introduction}

Serum protein electrophoresis in routine animal clinical chemistry laboratory testing allows the determination of the total $\gamma$-globulin fraction, but due to the poor resolution of the method, it cannot distinguish between the individual immunoglobulin classes such as IgG, IgM and IgA. Therefore sandwich enzymelinked-immuno-sorbent-assays (ELISAs) were established to quantitate the individual serum immunoglobulins, IgG, IgM, IgA, in order to follow the changes in these quantities in systemic tolerance studies in beagle dogs.

\section{Materials and Methods}

A total of 67 untreated beagle dogs (Breeder: Winkelmann, Germany) were employed in this study for determination of the immunoglobulin classes IgG, IgM and IgA. This population of animals consisted of two groups of beagle dogs from two experiments. Group A from the first experiment consisted of altogether 31 dogs (15 o and 16 ; weighing 7.5 to $16.2 \mathrm{~kg}$, aged 34 to 44 weeks $\hat{=} 0.8$ years) and group $B$ from the second experiment consisted of 36 dogs (21 $\sigma^{t}$ and 16 \%; weighing $10-$ $17 \mathrm{~kg}$, aged 82 to 240 weeks $\triangleq 1.6-4.6$ years). The animals were housed in individual cages under conventional conditions, and received a diet of Altromin ${ }^{\mathrm{H}}$ and tap water ad libitum. Prior to blood collection $(17-20 \mathrm{~h})$ the animals were fasted. Blood for the preparation of serum samples was collected from the v. jugularis without anaesthesia.
Polystyrene microtitre plates were obtained from Greiner (Solingen, Germany).

All three immunoglobulins, IgG, IgM and IgA were determined according to a sandwich ELISA using unlabelled affinity-purified goat anti-dog antibodies for coating and enzyme-labelled antibody for detection. Unlabelled and alkaline phosphataselabelled ${ }^{1}$ ), affinity-purified goat anti-dog IgG and anti-dog IgM antibody were obtained from Kirkegaard \& Perry Laboratories (Gaitherburg, USA). Unlabelled and horseradish peroxidaselabelled $^{1}$ ) affinity-purified goat anti-dog IgA antibody were obtained from Bethyl Laboratories (Montgomery, USA).

Purified dog IgG and IgM whole molecule (Chemicon, Temecula, USA) were used as standards. Purified dog IgA was not available commercially and therefore a $\operatorname{dog} \operatorname{IgA}$ reference serum was taken from a radial-immuno-diffusion (RID) kit (Bethyl Laboratories, Montgomery, USA) and used initially as a standard. Later, serum from one beagle dog (Breeder: Winkelmann, Germany) was calibrated against this serum in ELISA to be used as a standard for further determinations, to minimize the batch-to-batch variations of this commercially available reference serum. A separate serum pool from male and female beagle dogs was prepared for use as an internal quality control serum. All immunochemicals were stored in appropriate aliquots at $-25^{\circ} \mathrm{C}$, even when the manufacturer stipulated $4{ }^{\circ} \mathrm{C}$, because the results were also reproducible at $-25^{\circ} \mathrm{C}$. The enzymelabelled goat anti-dog IgA was stored at the prescribed $4{ }^{\circ} \mathrm{C}$.

\footnotetext{
1) Enzymes

Alkaline phosphatase (EC 3.1.3.1)

Horseradish peroxidase (EC 1.11.1.7)
} 
Phosphate-buffered saline tablets, $p$-nitrophenyl phosphate tablets (alkaline phosphatase substrate) ${ }^{1}$ ), 2,2'-azino-bis(3-ethylbenzthiazoline-6-sulphonic acid) tablets (horseradish peroxidase substrate) ${ }^{1}$ ) and Tween 20 were purchased from Sigma (Munich, Germany), whereas powdered substrate buffer from Boehringer (Mannheim, Germany) and sodium-dodecyl-sulphate were purchased from Bio-Rad (Munich, Germany). All other chemicals were of guaranteed reagent grade and obtained from Merck (Darmstadt, Germany) or Riedel de Haen (Seelze, Germany).

Phosphate-buffered saline (containing $137 \mathrm{mmol} / \mathrm{l} \mathrm{NaCl}, 2.7$ $\mathrm{mmol} / 1 \mathrm{KCl}, 10 \mathrm{mmol} / \mathrm{l}$ phosphate, $\mathrm{pH} 7.35$ ) was used as coating buffer. A solution containing $0.5 \mathrm{ml} / 1$ Tween 20 in demineralized water was used for washing, and phosphate-buffered saline containing $0.5 \mathrm{ml} / 1$ Tween 20 was used as the blocking solution and as the diluent for standards, samples and enzyme-labelled antibodies.

The phosphatase substrate solution contained $3.8 \mathrm{mmol} / \mathrm{l} p$ nitrophenyl phosphate, $0.5 \mathrm{mmol} / \mathrm{l}$ magnesium chloride, 1.01 mol/l diethanolamine adjusted to $\mathrm{pH} 9.8$ with $\mathrm{HCl}$. The stop solution used was $3 \mathrm{~mol} / \mathrm{l} \mathrm{NaOH}$.

The horseradish peroxidase substrate buffer was prepared from powdered material (Boehringer: Mannheim, Germany); the substrate solution contained $1.9 \mathrm{mmol} / 1$ 2,2'-azino-bis(3-ethylbenzthiazoline-6-sulphonic acid), $3.2 \mathrm{mmol} / 1$ sodium perborate and $100 \mathrm{mmol} / 1$ phosphate/citrate $\mathrm{pH} \mathrm{4.4}$. The stop reagent was a $10 \mathrm{~g} / 1$ aqueous solution of sodium-dodecyl-sulphate.

A micro-plate washer (Model 1550, Bio-Rad) was used to wash the plates and a dilutor (Microlab 1000, Hamilton) was used to dilute the standards and samples. Absorbances of developed enzymatic reactions were determined on a microplate reader (Model 3550, Bio-Rad).

Microtitre plates were separately coated with $100 \mu$ l of unlabelled antibody $(5 \mathrm{mg} / \mathrm{l})$ per well for $12-72 \mathrm{~h}$ at $4{ }^{\circ} \mathrm{C}$. After coating, the plates were washed with washing solution $(300 \mu \mathrm{l} /$ well) three times, and unbound sites were blocked with $250 \mu \mathrm{l}$ blocking solution/well, at $37^{\circ} \mathrm{C}$ for one hour. Thereafter the blocking solution was decanted. Duplicates of diluent (blanks), standards and appropriate diluted serum samples, each consisting of $100 \mu \mathrm{l} /$ well, were incubated at $37^{\circ} \mathrm{C}$ for $2 \mathrm{~h}$. The plates were washed again three times and appropriately diluted enzyme-labelled antibodies $(100 \mu \mathrm{l} /$ well $)$ were added and further incubated at $37^{\circ} \mathrm{C}$ for $2 \mathrm{~h}$. The washing was repeated, then 100 $\mu$ l substrate solution per well were added and incubated at $37^{\circ} \mathrm{C}$ for $45 \mathrm{~min}$. The colour reaction was terminated by adding $50 \mu \mathrm{l}$ of stop solution. The absorbance was read at $405 \mathrm{~nm}$ for both substrates and measured against a reference wavelength $(655 \mathrm{~nm}$ for $p$-nitrophenyl phosphate; $490 \mathrm{~nm}$ for 2,2'-azinobis(3-ethylbenzthiazoline-6-sulphonic acid). The concentrations of standards used for IgG, IgM and IgA ELISAs were 5, 10, $15,20 \mu \mathrm{g} / \mathrm{l} ; 25,50,100,150 \mu \mathrm{g} / \mathrm{l}$ and $50,100,200,300,400$ $\mu \mathrm{g} / \mathrm{l}$, respectively. Serum samples were diluted to $1: 600000$ for IgG and $1: 10000$ for IgM and IgA. To measure IgG and IgM concentrations, phosphatase-labelled antibodies (stock solution $0.1 \mathrm{~g} / \mathrm{l})$ were diluted $1: 1000$ and $1: 500$ and horseradish peroxidase-labelled anti-dog $\operatorname{IgA}(1 \mathrm{~g} / \mathrm{l})$ was diluted $1: 2500$.

The serum immunoglobulin concentrations of all samples were calculated from the standard curve which was obtained from the best fit line of each data point by linear regression.

\section{Statistical analysis}

For the statistical analysis, the two groups A and B were compared by one-sided Wilcoxon tests for an age-dependent increase in $\operatorname{IgG}, \operatorname{IgM}$ and $\operatorname{IgA}$ serum concentrations, since it is assumed that there is no difference between the sexes, with respect to the immunoglobulin concentrations. (Within group A, a two-sided Wilcoxon test was conducted to see whether there were differences between the two sexes.)
Moreover, for the second group a covariance analysis was performed with sex as a factor and age as a covariate. In view of the wide age range and different distributions of age for each sex, this seemed to be appropriate. For the covariance analysis, the p-values were calculated according to type III sum of squares. The results of the tests are presented as p-values, which were obtained by approximation in the case of the non-parametric tests.

\section{Results}

The typical standard curves for dog IgG, IgM and IgA ELISAs are illustrated in figure 1.

As can be seen, the standard curves are linear within a range of $5-20 \mu \mathrm{g} / \mathrm{l}, 25-150 \mu \mathrm{g} / \mathrm{l}$ and $50-400 \mu \mathrm{g} / \mathrm{l}$ for IgG, IgM and IgA, respectively. For all three standard curves the correlation coefficient calculated
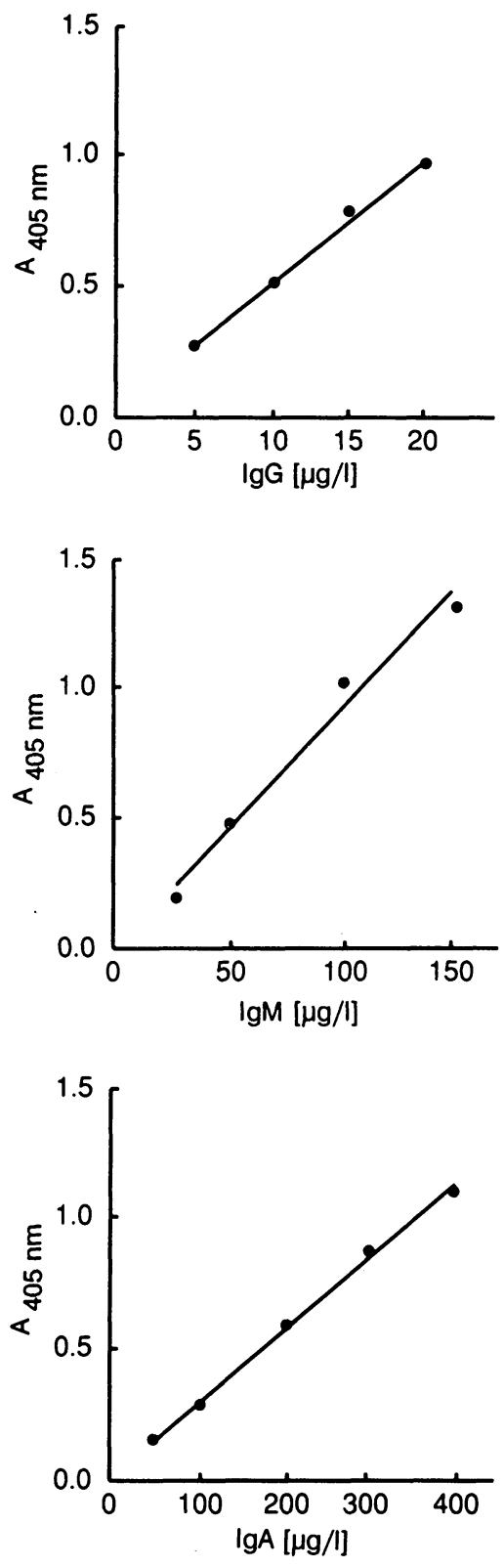

Fig. 1. Typical IgG, IgM and IgA sandwich ELISA standard curves 
by linear regression analysis was in the range of 0.989 to 0.999 . The detection limits for the $\operatorname{IgG}, \operatorname{IgM}$ and IgA sandwich ELISAs were $5 \mu \mathrm{g} / 1,25 \mu \mathrm{g} / \mathrm{l}$ and 50 $\mu \mathrm{g} / \mathrm{l}$, respectively. The coefficient of variation (CV) for the within-run reproducibility for IgG, IgM and IgA was $4.7 \%$ to $6.7 \%$ ( 40 measurements of one single sample per day) and the CV for between-run reproducibilities for IgG, IgM and IgA was $5.1 \%$ to $12.7 \%$ (measurements on 10 to 13 different working-days). The specificity of the IgG, IgM and IgA ELISAs was examined by analysing the cross-reactivity of purified IgG and IgM immunoglobulins. Using different concentrations of these purified IgG and IgM immunoglobulins it was found that neither IgG nor IgM ELISAs exhibited cross-reactivity towards IgM and $\operatorname{IgA}$ or $\operatorname{IgG}$ and $\operatorname{IgA}$, respectively. However, in the IgA ELISA about $5 \%$ and $10 \%$ cross-reaction were observed as calculated at the physiological concentrations of about $7300 \mathrm{mg} / \mathrm{l} \mathrm{IgG}$ and $770 \mathrm{mg} / 1 \mathrm{IgM}$. Though no purified IgA was commercially available, no cross-reaction in IgG and IgM ELISAs is expected, as sera with high $\operatorname{IgA}$ concentrations $(\approx 3500 \mathrm{mg} / \mathrm{l})$ showed average physiological IgG $(\approx 7300 \mathrm{mg} / \mathrm{l})$ and $\operatorname{IgM}(\approx 770 \mathrm{mg} / \mathrm{l})$ concentrations.

The immunoglobulin concentrations found in age group A and age group B are summarized in table 1.

For the covariance analysis, one animal showing extremely high serum IgA (7230 mg/l) and IgG (12 290 $\mathrm{mg} / \mathrm{l})$ concentrations was considered to be an outlier and was excluded from this covariance analysis. A significant influence of sex on the results could not be detected. In our opinion the analyses do not show an age-dependent effect either. The slopes of the estimated regression lines were 0.6 (standard error 0.52 ) for IgG, $0.2(0.1)$ for IgM and $0.4(0.34)$ for IgA.

\section{Discussion and Conclusion}

The serum concentrations of the immunoglobulins, IgG, IgM and IgA, in beagle dogs, determined with a newly developed ELISA in this study, are in the range of those already known from the literature for different dog species. These literature values were determined mainly by radial immuno-diffusion
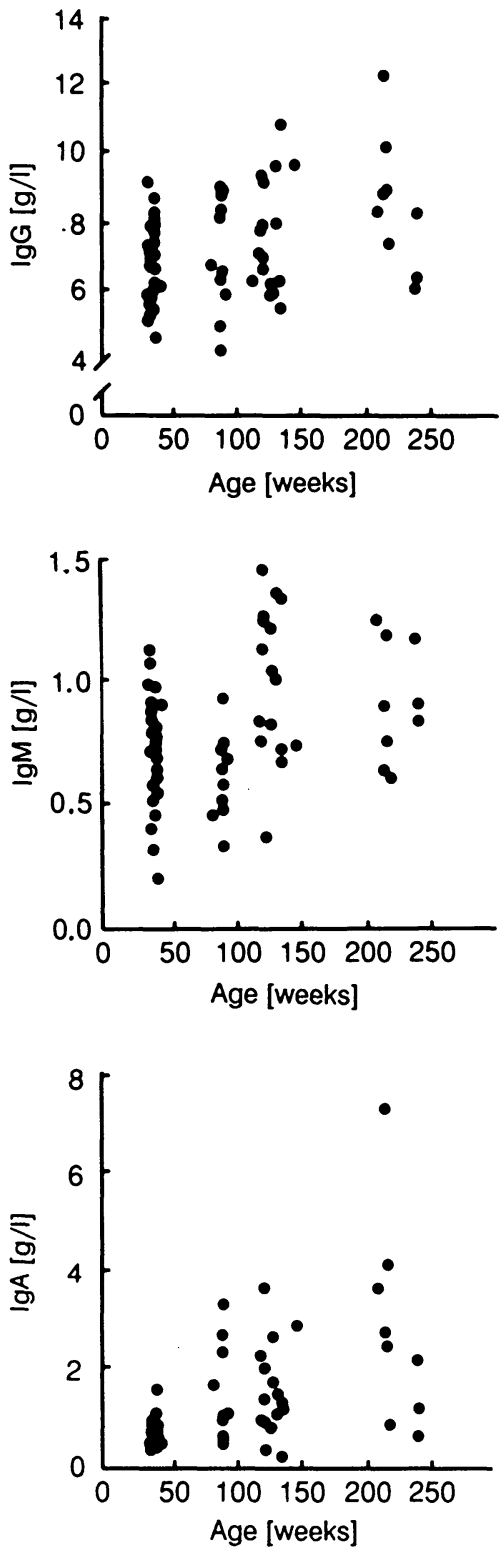

Fig. 2. Concentrations in serum of IgG, IgM and IgA immunoglobulins in normal, untreated beagle dogs $(n=67)$

$(1-7)$. In various dog species, such as collies (1), Airdale terriers (2), Swiss cattle dogs, German shepherds (3), mongrels $(4,5)$ and beagles $(6,7)$ the concentrations of the three immunoglobulins ranged from $360-32800 \mathrm{mg} / \mathrm{l} \mathrm{IgG}, 130-3000 \mathrm{mg} / \mathrm{l} \mathrm{IgM}$ and $130-2800 \mathrm{mgl}$.

Tab. 1. Concentrations of $\operatorname{IgG}, \operatorname{IgM}$ and $\operatorname{IgA}(\mathrm{mg} / \mathrm{l})$ in the sera of beagle dogs determined by sandwich ELISA (mean \pm SD)

\begin{tabular}{|c|c|c|c|c|}
\hline \multirow[t]{2}{*}{ Immunoglobulin } & \multicolumn{2}{|c|}{$\begin{array}{l}\text { Age group } A \\
34-44 \text { weeks of age }(N=31)\end{array}$} & \multicolumn{2}{|c|}{$\begin{array}{l}\text { Age group B } \\
82-240 \text { weeks of age }(\mathrm{N}=36)\end{array}$} \\
\hline & $\overline{\mathrm{x}} \pm \mathrm{SD}$ & Range & $\overline{\mathrm{x}} \pm \mathrm{SD}$ & Range \\
\hline $\operatorname{IgG}(\mathrm{mg} / \mathrm{l})$ & $6860 \pm 1130$ & $4570-9160$ & $7740 \pm 1720$ & $4350-12290$ \\
\hline $\operatorname{IgM}(\mathrm{mg} / \mathrm{l})$ & $700 \pm 210$ & $190-1110$ & $840 \pm 310$ & $320-12290$ \\
\hline $\operatorname{IgA}(\mathrm{mg} / \mathrm{l})$ & $580 \pm 250$ & $260-1480$ & $1790 \pm 1380$ & $180-7230$ \\
\hline
\end{tabular}


Glickman et al. (7), using a large beagle population, observed an age-dependent increase for all three immunoglobulin classes (IgG, IgM and $\operatorname{IgA}$ ), whereas in our beagles, held under standardized pathogen-free conditions, a distinct age-dependent increase was only observed in IgA serum concentrations. This may be due to the differences in general health conditions of the dogs, as the large population $(\mathrm{N}=929)$ of Glickman et al. (7) also included animals with various infections.

\section{References}

1. Reynolds, H. Y., Dale, D. C., Wolff, S. M. \& Johnson, J. S. (1971) Serum immunoglobulin levels in grey collies (35314). Proc. Soc. Exp. Biol. Med. 136, 574-577.

2. Barta, O., Turnwald, G. H., Shafter, L. M. \& Pourcian, S. S. (1985) Blastogenesis-suppressing serum factors decreased immunoglobulin $A$, and increased $\beta 1$ globulins in Airdale Terriers with diskospondylitis. Am. J. Vet. Res. 46, 13191322.

3. Bichsel, P., Vandelvelde, M., Vandelvelde, E., Affolter, M. \& Stister, H. (1984) Immunoelectrophoretic determination of albumin and IgG in serum and cerebrospinal fluid in dogs with neurological diseases. Res. Vet. Sci. 37, 101-107.

4. Day, M. J. \& Penhale, W. J. (1988) Serum immunoglobulin A concentrations in normal and diseased dogs. Res. Vet. Sci. $45,360-363$.
The ELISA developed in this study has the advantages of reproducibility, sensitivity and less cross-reactivity. Moreover it is more economical than RID, may be automatized and may be used for immunotoxicological characterization of various compounds, especially in long-term studies in beagle dogs; however, the age distribution of the animals has to be considered in planning animal studies, in view of the clear agedependence found for the immunoglobulin $\mathrm{A}$.

5. Reynolds, H. Y. \& Johnson, J. S. (1970) Quantitation of canine immunoglobulins. J. Immunol. 105, 698-703.

6. Vriesendorp, H. M., Halliwell, R. E., Johnson, P. M., Fey, T. A. \& Mc Donough, C. M. (1985) Immunoglobulin levels in dogs after total body irradiation and bone marrow transplantation. Transplantation 39, 583-588.

7. Glickman, L. T., Shoter, F. S., Payton, A. J., Laster, L. L. \& Felsbeerg, P. J. (1988) Survey of serum IgA, IgG and IgM concentrations in a large beagle population in which IgA deficiency had been identified. Am. J. Vet. Res. 49, $1240-$ 1245.

Akhil S. Bhargava

Research Laboratories Schering AG

Experimental Toxicology

Müllerstraße 170-178

Postfach 650311

W-1000 Berlin 65

Bundesrepublik Deutschland 